\title{
Entrepreneurial Self-Identity, Perceived Corruption, Exogenous and Endogenous Obstacles as Antecedents of Entrepreneurial Intention in Italy
}

\author{
Francesco Ceresia $^{*}+(\mathbb{D})$ and Claudio Mendola ${ }^{\dagger}$ \\ Department of Political Science and International Relations, University of Palermo, 90134 Palermo PA, Italy; \\ mendola.claudio@gmail.com \\ * Correspondence: francesco.ceresia@unipa.it; Tel.: +39-339-232-4611 \\ + These authors contributed equally to this work.
}

Received: 8 February 2019; Accepted: 11 February 2019; Published: 14 February 2019

\begin{abstract}
Although entrepreneurship is considered one of the most powerful drivers of national economies around the world, there is little consensus about what informal factors foster entrepreneurial intention. In accordance with recent literature, entrepreneurial self-identity perception, the perception of corruption in the entrepreneurship ecosystem, and perceived exogenous and endogenous obstacles to entrepreneurship were hypothesized as antecedents of college students' and graduates' entrepreneurial intention. A study with a sample $(\mathrm{N}=153)$ composed of college students and graduates from an Italian university was conducted. A hierarchical multiple regression analysis was performed to test the research hypotheses. The hypotheses that entrepreneurial self-identity perception and corruption perception of the entrepreneurial ecosystem are positive antecedents of entrepreneurial intention were confirmed. Corruption was considered as a viable and socially acceptable strategy that entrepreneurs might adopt in order to easily overcome governmental norms and rules about managing firms. It was hypothesized that the perception of corruption of the entrepreneurial ecosystem might be a positive antecedent of entrepreneurial intention if the subjects perceived the corruption as pervasive of the economic ecosystem and the effort made by national government to control corruption as ineffective. From this point of view, the positive causal relationship between perceived corruption and entrepreneurial intention could reveal college students and graduates' propensity to perceive corruption as a phenomenon capable of generating a "grease the wheel" effect.
\end{abstract}

Keywords: entrepreneurial intention; entrepreneurial self-identity; corruption; exogenous obstacles; endogenous obstacles

\section{Introduction}

Entrepreneurship is generally recognized as one of the key economic drivers of a country due to its ability to make efficient use of entrepreneurs' innovative and creative ideas through patent registration, the development of technologically up-to-date ideas and the engineering of intellectually stimulating workplaces. Many studies have demonstrated that entrepreneurship can be directly linked to the creation of new jobs, to sustaining a country's wealth, and indirectly to a positive impact on the social environment (Aidis et al. 2012; Aparicio et al. 2016; Engle et al. 2010; Holcombe 1998; Lucas and Fuller 2017; Samila and Sorenson 2011; Wennekers and Thurik 1999). In general terms, researchers share a common vision in which entrepreneurship can be considered as one of the principal sources of a country's economic and social growth (Aparicio et al. 2016). It is not surprising that the literature has focused on the analysis of factors capable of fostering entrepreneurship development. 
However, it has not been easy to clearly identify such factors, nor the mechanism through which these factors lead entrepreneurs to value and take advantage of their potential (Anokhin and Schulze 2009; Estrin et al. 2013).

In the search to identify factors capable of fostering the development of an entrepreneurial ecosystem, North (1991) proposed distinguishing these factors-also referred to as institutions-into two categories: formal and informal. On one hand, the formal rules or institutions represent the complex system of rules and laws adopted by a nation to economically incentivize the creation and management of firms. Among these factors, for example, are the lists of conditions an entrepreneur must fulfil in order to obtain the credit or the amount of money needed to start a firm (Aparicio et al. 2016; North 1991, 2005). On the other hand, informal constraints or institutions are linked to the complex system of values, norms, beliefs and attitudes capable of influencing the way in which the formal factors are perceived and utilized by individuals. Among these factors we find variables such as entrepreneurial attitude, self-perception as a potential entrepreneur, perceptions of the pervasiveness of corruption, the attitude towards the intensity and effectiveness of efforts made by local government to fight corruption, and the perceived endogenous and exogenous obstacles that can hinder an entrepreneurial career (Aparicio et al. 2016; Neneh 2014; North 1991; Stenholm et al. 2013).

Some authors have stressed that informal factors have a greater impact on the individual's intention of starting and managing a firm than formal ones (Aparicio et al. 2016; Thornton et al. 2011), since the former are associated with intrinsic motivational variables and the latter with extrinsic motivational ones (Neneh 2014). Taking this point into account, it becomes very interesting to identify the informal factors capable of having a significant motivational impact on the decision to embark on an entrepreneurial career. The main purpose of this study was to verify the hypotheses according to which entrepreneurial self-identity, perceived corruption of the entrepreneurial ecosystem, and perceived exogenous and endogenous obstacles to entrepreneurial growth can be considered as antecedents of entrepreneurial intention in a sample composed of Italian college students and graduates.

\section{Entrepreneurial Self-Identity and Entrepreneurial Intention}

The entrepreneurial literature of recent years has seemed to go in the direction of investigating the role of self-identity perception in entrepreneurs. This construct has been described as the meaningful categories and characteristics an individual identifies with, in order to interpret situations and his/her own actions, both at the initial stage of the venturing process and during the company's ongoing management. It is possible to identify two main theories elaborated by scholars in order to explain the role of self-identity in an entrepreneurial context (Alsos et al. 2016; Brändle et al. 2018; Conger et al. 2012; Donnellon et al. 2014; Fauchart and Gruber 2011; Rise et al. 2010; Sieger et al. 2016).

\subsection{The Role of Person Identities in Shaping Entrepreneurial Behavior}

Conger et al. (2012) focused on the driving force guiding entrepreneurs in choosing specific company goals by embracing the Identity Control Theory (ICT) (Burke 2004, 2007). The theory proposed by Burke $(2004,2007)$ underlines that the construct called "self-identity" should be considered as being composed of three independent sub-identities that work together to create a coherent general self-identity. More specifically, the ICT categorizes these three sub-identities as follows: person identities, role identities and social identities (Hoang and Gimeno 2010). Person identities are based on culturally recognized characteristics internalized by the individual that make him or her a unique individual (e.g., I identify and behave accordingly to my own internal thoughts, inclinations or values). Role identities are based upon the social position an individual occupies in the social structure (e.g., I identify with, and behave in accordance with, my position). Finally, social identity describes characteristics that an individual derives from belonging to a particular social group (e.g., I identify with characteristics typically associated with males because I am a man) (Burke 2004, 2007).

Conger et al. (2012) considered the person identities as trans-situational master identities that can be ranked on a scale with two opposing poles: the self-enhancement pole, which is characterized 
by an interest in achieving personal success, and the self-transcendence pole, which refers to particular attention to the welfare of others. According to their results, person identities could affect entrepreneurs' behavior and choices in two ways: directly, through the setting of a specific goal for the venture, or indirectly, through the enacting of complementary contextual identities, such as role identities. Moreover, these authors suggested that person identities, as an expression of individual values, might be considered as a bridge between personal belief and actual entrepreneurial intention (Conger et al. 2012). This assumption can be considered in line with the work of Rise et al. (2010) that showed the important role played by self-identity in shaping behavioral intention.

\subsection{The Role of Social Identities in Shaping Entrepreneurial Behavior}

Fauchart and Gruber (2011) proposed a model based on the Social Identity Theory (Tajfel and Turner 1979) that suggests that entrepreneurial identity can be categorized into three independent social identity types, according to the entrepreneur's driving motivational force, self-evaluation and frame of reference: (a) the Darwinian type, characterized by a pursuit of economic goals assuming competitive behavior as the primary way of behaving in the social space; (b) the Communitarian type, characterized by a desire to support and receive support from the local community through innovation and action; (c) the Missionary type, characterized by the need to achieve results related to a particular cause (either political or social) in order to make the world a better place. This model has received great empirical support (Sieger et al. 2016). Brändle et al. (2018) showed that the identities more oriented to the Darwinian and Communitarian types were more associated with entrepreneurial self-efficacy in potential entrepreneurs, which can be considered as one of the key psychological factors affecting the start-up process. Alsos et al. (2016) revealed how the three types of social identity can guide entrepreneurs in choosing the right direction and strategy for their firms in situations of economic uncertainty (Sarasvathy 2001). More specifically, Darwinian and Missionary entrepreneurs can be considered as two social identity types characterized by a decision making process based on causation principles that follow a logic of prediction (e.g., using pre-existent market knowledge to maximize the probability of achieving their goals, whether economic or political, through planning and analysis), whereas Communitarian entrepreneurs are more guided by effectual principles that follow a logic of control (i.e., they try to control the future by defining preventive agreements with potential partners to avoid unaffordable future losses, since their aim is to serve the community they belong to) and are driven by causation principles only in the early stage of the start-up process. As underlined by Fauchart and Gruber (2011), these results seem to provide evidence that there is a good fit between identity type and the entrepreneurial choice when three independent variables are considered: (a) the choice of the marketplace, (b) the concern for customers, and (c) the ability to use resources and the firm's capabilities efficiently. However, the rigid structure of the three independent social identity types can be considered as one of the great limitations of this theory. Many authors, in fact, suggest that entrepreneurs should be considered as carriers of an identity based on multiple sources combined according to context, situation, and stage of the firm's life (Alsos et al. 2016; Fauchart and Gruber 2011).

\subsection{The Relationship between Entrepreneurial Self-Identity and Entrepreneurial Intention}

Although there are many different models and theories about the motivational role of entrepreneurial self-identity in entrepreneurial behavior, scholars agree with the predictive role of identity perception, considering it as a way that individuals confirm their beliefs (Conger et al. 2012; Obschonka et al. 2012) — thus avoiding a state of cognitive dissonance (Festinger 1957)—and perceive their self-efficacy (Brändle et al. 2018; Cardon et al. 2009). Moreover, some authors have underlined the potential effect of identity aspiration on behavior, such as career decisions and planning, stating that an individual's present behavior could be guided partially by the distinctive characteristics of a social group the individual wants to join in the future (Alsos et al. 2016; Watson 2013). These considerations have led some scholars who study entrepreneurship education to consider the development of an entrepreneurial identity as one of the top priorities of entrepreneurial courses, given 
its role in determining entrepreneurial competency and driving motivational energy, which in turn affects future entrepreneurial behaviors (Alsos et al. 2016; Donnellon et al. 2014; Zhang et al. 2014). Since our research sample consisted of college students and young graduates in Italy, we decided to investigate self-identity perception using items not specifically focused on a single type of entrepreneurial identity - such as those described by Fauchart and Gruber (2011) that could be applied more effectively to actual entrepreneurs-but rather oriented towards measuring how many of our participants identified with a socially shared idea about what it means to be an entrepreneur. Following Conger et al. (2012), for the purpose of this study, we defined the entrepreneurial self-identity construct as self-perception about internalized characteristics that are culturally recognized as distinctive of entrepreneurs and, based on the previous statements, we hypothesized that:

Hypothesis 1. Entrepreneurial self-identity is a positive antecedent of entrepreneurial intention; that is, a higher level of entrepreneurial self-identity will predict a higher level of entrepreneurial intention.

\section{Perceived Corruption and Entrepreneurial Development}

The growing interest of many scholars in the relationship between corruption, economic growth and entrepreneurial development is justified by the pervasiveness of the phenomenon of corruption in the entrepreneurial activities in many countries, even in Europe (Aidis et al. 2012; Del Mar Salinas-Jiménez and Salinas-Jiménez 2007; Dutta and Sobel 2016; Glaeser and Saks 2006; Hanoteau and Vial 2014; Mauro 1995). Defined as criminal activity conducted by public officers to obtain private monetary and non-monetary gain (Anokhin and Schulze 2009; Glaeser and Saks 2006), corruption seems to have a controversial relationship with entrepreneurial development. Even though many studies have focused on exposing the effects of corruption on a country's economic growth, industrialization and entrepreneurial development, the results have been mostly inconclusive or discordant (Anokhin and Schulze 2009; Glaeser and Saks 2006; Hanoteau and Vial 2014; $\mathrm{Li}$ and $\mathrm{Wu}$ 2010). In the literature, it is possible to find two opposite positions regarding the real effect of corruption on the economic and entrepreneurial fabric of the country; that is, the hypothesis labeled "grease the wheels" and the hypothesis labeled "sand the wheels", respectively (Hanoteau and Vial 2014; Li and Wu 2010; Xu and Yano 2017).

\subsection{The "Sand the Wheel" Hypothesis}

Supporters of the "sand the wheel" hypothesis emphasize that corruption has a negative effect on entrepreneurial activities and a country's economic growth (Del Mar Salinas-Jiménez and Salinas-Jiménez 2007; Dutta and Sobel 2016; Paunov 2016). Del Mar Salinas-Jiménez and Salinas-Jiménez (2007) reported that corruption has a negative influence on a country's economy by lowering its productivity levels and economic growth rate. In a recent study, Xu and Yano (2017) identified two principal problems that entrepreneurs face while working in an economic and production system characterized by a high level of corruption: expropriation and rent-seeking. The problem of expropriation refers to a situation in which firms that invest money and resources in research and development $(R \& D)$ cannot be sure their patents will succeed economically since corrupt public officers could hinder them or, at the extreme, their intellectual properties could be expropriated in order to favor competitors with whom public officers have colluded. This phenomenon gives firms a sense of uncertainty about achieving their expected return on investment and leads them to economically downsize their R\&D department, slowing the birth of new technologically advanced ideas. The rent-seeking problem is a direct consequence of the bribes paid by entrepreneurs who end up reducing investment in company innovation and productivity, as they invest part of the firm's resources in payments to corrupt public officers and government agents. This is particularly true for small and medium enterprises that have lower profit margins and smaller investment capabilities than larger ones (Hunt and Laszlo 2012; Paunov 2016). 
Moreover, Hanoteau and Vial (2014) stated that given the presence of competitors who obtain commercial advantages from their inclination to corrupt, honest entrepreneurs might encounter substantial obstacles to entering certain markets due to the great difficulty of obtaining licenses, permissions and patents (Paunov 2016). These scholars have underlined that corruption has a strong negative effect on the economy and growth rate of a country by sanding the wheel of entrepreneurship, even when a country's business climate is poor (Dutta and Sobel 2016; Xu and Yano 2017).

\subsection{The "Grease the Wheel" Hypothesis}

The scholars who support the "grease the wheel" hypothesis, have instead stressed the idea of corruption as having a positive effect on a country's economic development, especially when the complex system of norms and rules forces new firms to endure lengthy procedures and to have certain characteristics that can be seen as obstacles to the development and realization of entrepreneurial initiatives (Dreher and Gassebner 2013; Hanoteau and Vial 2014). In countries characterized by high levels of bureaucracy and low levels of economic development, corruption seems to play the role of an economic catalyzer, due to its ability to help entrepreneurs overcome the administrative procedures and controls needed to open a firm or to commercialize a product or service, since obtaining credit and licenses from authorities through legal channels seems to be a very arduous road (Hanoteau and Vial 2014). Moreover, some authors have stated that the "bottleneck" effect, which prevents firms from freely accessing the market due to the impossibility of, or their unwillingness to, bribe officials in order to obtain unlawful advantages, could be seen as a positive in order to avoid the excessively high presence of competitors in the market (Dreher and Gassebner 2013).

\subsection{Can "Grease the Wheel" and "Sand the Wheel" Coexist?}

Hanoteau and Vial (2014) maintain that the two above-mentioned hypotheses- "grease the wheel" and "sand the wheel" - could coexist within the same production ecosystem if the existing contextual differences between firms, for example size, were carefully taken into account (Zhou and Peng 2012). Zhou and Peng (2012) showed that corruption and bribery could have more advantages for big firms than for small and medium firms, due to the greater financial resources of the former. As Hanoteau and Vial (2014, p. 1) suggested: "we argue that the grease and sand-the-wheel effects are likely to co-exist among a large number of firms, and that the industrial effect of corruption depends on the productivity drivers that fuel firm's dynamics". However, the debate about which of the two hypotheses fits best with the empirical data seems to favor the idea that corruption creates a "sand the wheel" effect on the entrepreneurial ecosystem (Dutta and Sobel 2016). This is true also because corruption contributes greatly to creating a climate of distrust in regard to public authorities, which can severely deter the intention of younger potential entrepreneurs, dissuading them from starting an entrepreneurial career (Djankov et al. 2005; Dutta and Sobel 2016; Estrin et al. 2013).

\subsection{The Effect of Corruption Perception of the Entrepreneurship Ecosystem on Entrepreneurial Intention}

Although the majority of studies seem to confirm the "sand the wheel" hypothesis as the one that better explains the relationship between entrepreneurship, economic growth, and corruption (Aidt 2009; Allini et al. 2017; Bowen and De Clercq 2008; Del Mar Salinas-Jiménez and Salinas-Jiménez 2007; Djankov et al. 2005; Dutta and Sobel 2016; Estrin et al. 2006; Olawale and Garwe 2010), El Harbi and Anderson (2010) have developed an econometric model that indirectly supports the "grease the wheel" hypothesis (Hofstede et al. 2004), as they showed that lower levels of perceived corruption were associated with lower levels of self-employment. These authors suggest that this apparently counter-intuitive and counter-trend result could be explained by taking into account entrepreneurs' resignation to, and understanding of, corruption as something they are used to and against which they have developed specific competencies (El Harbi and Anderson 2010). In other words, corruptive phenomena are treated as something inevitable, something that is part of their daily work (Djankov et al. 2005). Aidis et al. (2012) underlined that under certain circumstances, corruption 
can be seen as a source of equilibrium rather than of chaos for the entrepreneurial ecosystem since, after having been assimilated into a country's culture and becoming something capable of producing stability, corruption allows the entrepreneurs to respond efficiently to the complexity and uncertainty that is typical of business activities (Hanoteau and Vial 2014; El Harbi and Anderson 2010).

These counter-intuitive considerations about the effect of corruption perception on entrepreneurial dynamics, especially in countries where corruption is perceived as an ever-present dimension and the economic actors have generally learnt how to deal with it, must be considered before formulating any research hypothesis about the relationship between corruption and the entrepreneurial intention of Italian college students and graduates. Hence, we considered it necessary to undertake a preliminary analysis of Italians' attitudes towards, and perceptions of, corruption, taking into account the particular political and social environment in which they live. Therefore, we briefly discuss the Italian perception of corruption and the efforts the Italian government has made to effectively combat it.

\subsection{Corruption Perception of the Entrepreneurship Ecosystem and Entrepreneurial Intention in Italy}

It is possible to identify two principal indicators of a country's legality, both representing the population's perceptions of the local pervasiveness of the phenomenon of corruption (Dutta and Sobel 2016; Olken 2009; Paunov 2016), and there is substantial agreement among scholars that corruption perception can be considered as a reliable indicator of the real and objective level of corruption existing within a country (Olken 2009).

Figure 1 shows the trend of Italy's scores on the Corruption Perception Index (CPI) compared with the trend of CPI average scores of EU and Western European countries, which represent levels of corruption perception ( $100=$ lowest level of corruption; $0=$ highest level of corruption) assigned by Transparency International for the period 2006-2017. Even though the Italian CPI score is clearly lower than the CPI average score of EU and Western European countries, the Italian trend underwent great negative fluctuations especially during the global economic crisis (2008), while it slowly began to rise by the year 2012 and finally reached a level in 2017 that placed it in 54th position worldwide and in the fourth quartile in the EU and Western Europe.

Figure 2 shows a World Bank data comparison between the Italian and EU and Western European (average value) population's perception of the efforts made by governments to control and prevent corruption. Scores on this indicator can vary between -2.5 and +2.5 , where higher scores mean that the population perceives the anti-corruption strategies adopted by government as effective. The trend observable in Figure 2 seems to be in line with the trend shown in Figure 1: i.e., over the last fifteen years, it is possible to observe a high and constantly growing breach between the perception of the efforts made by the Italian government and those of EU and Western European governments (average value).

This last indicator takes on even greater meaning, as recent studies have shown that the perception of living in a country where the government actively fights against corruption has a positive impact on entrepreneurial dynamics through the creation of expectations based on trust among younger potential entrepreneurs regarding a positive outcome to their monetary and non-monetary investments (Aparicio et al. 2016; Xu and Yano 2017), thus enhancing their entrepreneurial intention (Aidis et al. 2012). Since we can observe limited attention of the Italian government to the issue of corruption control and a shared perception of a relatively high level of corruption among Italians-clearly related to Italy being a European country and among the most developed nations in the world-and also following the statements made by El Harbi and Anderson (2010), we hypothesized that:

Hypothesis 2. The perception of corruption of the entrepreneurial ecosystem is a positive antecedent of entrepreneurial intention; that is, a higher level of perception of corruption in the entrepreneurial ecosystem predicts a higher level of entrepreneurial intention. 


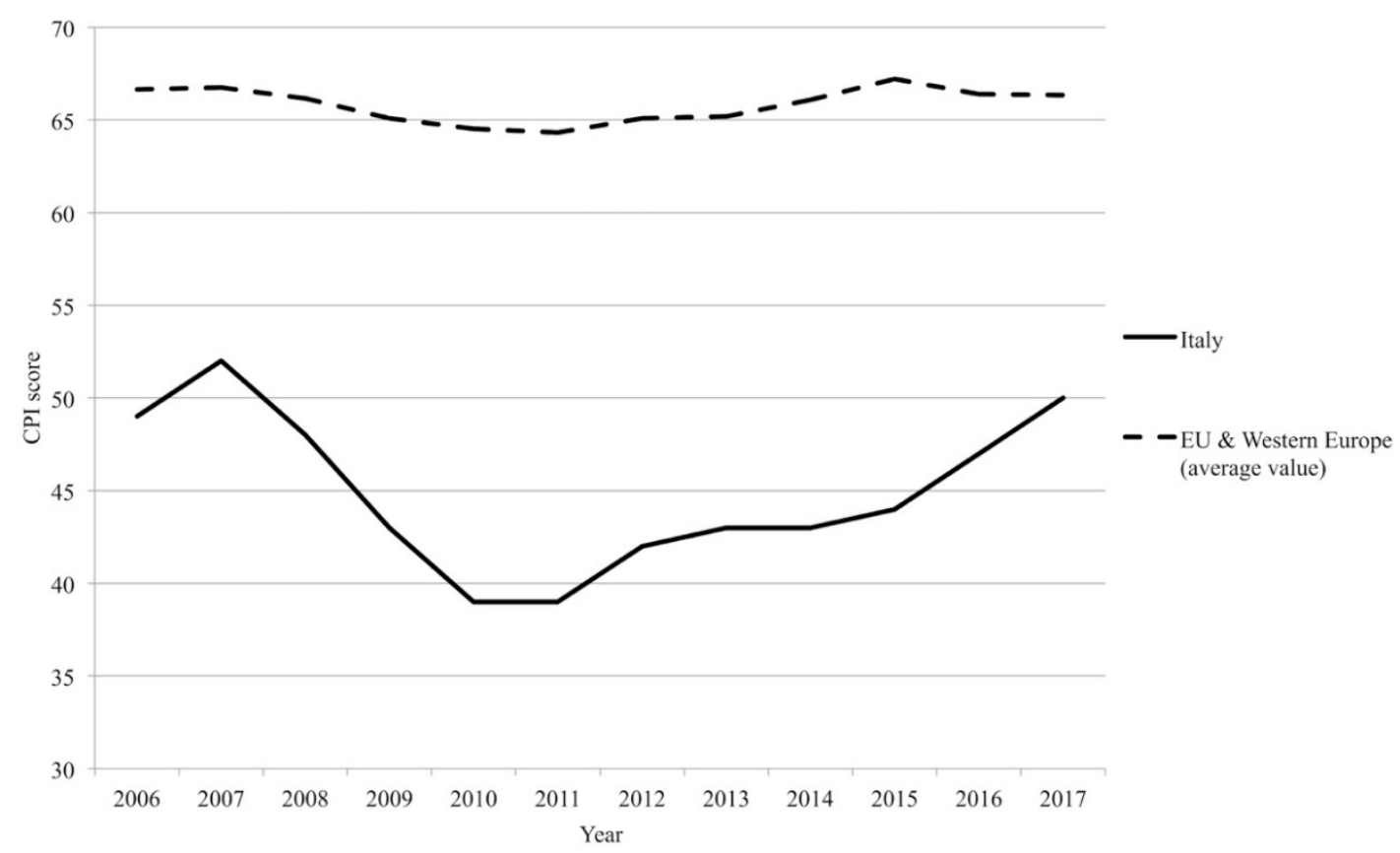

Figure 1. Corruption Perception Index trend in Italy and in the EU and Western Europe (average value) for the period between 2006 and 2017. Source: Transparency International (2017).

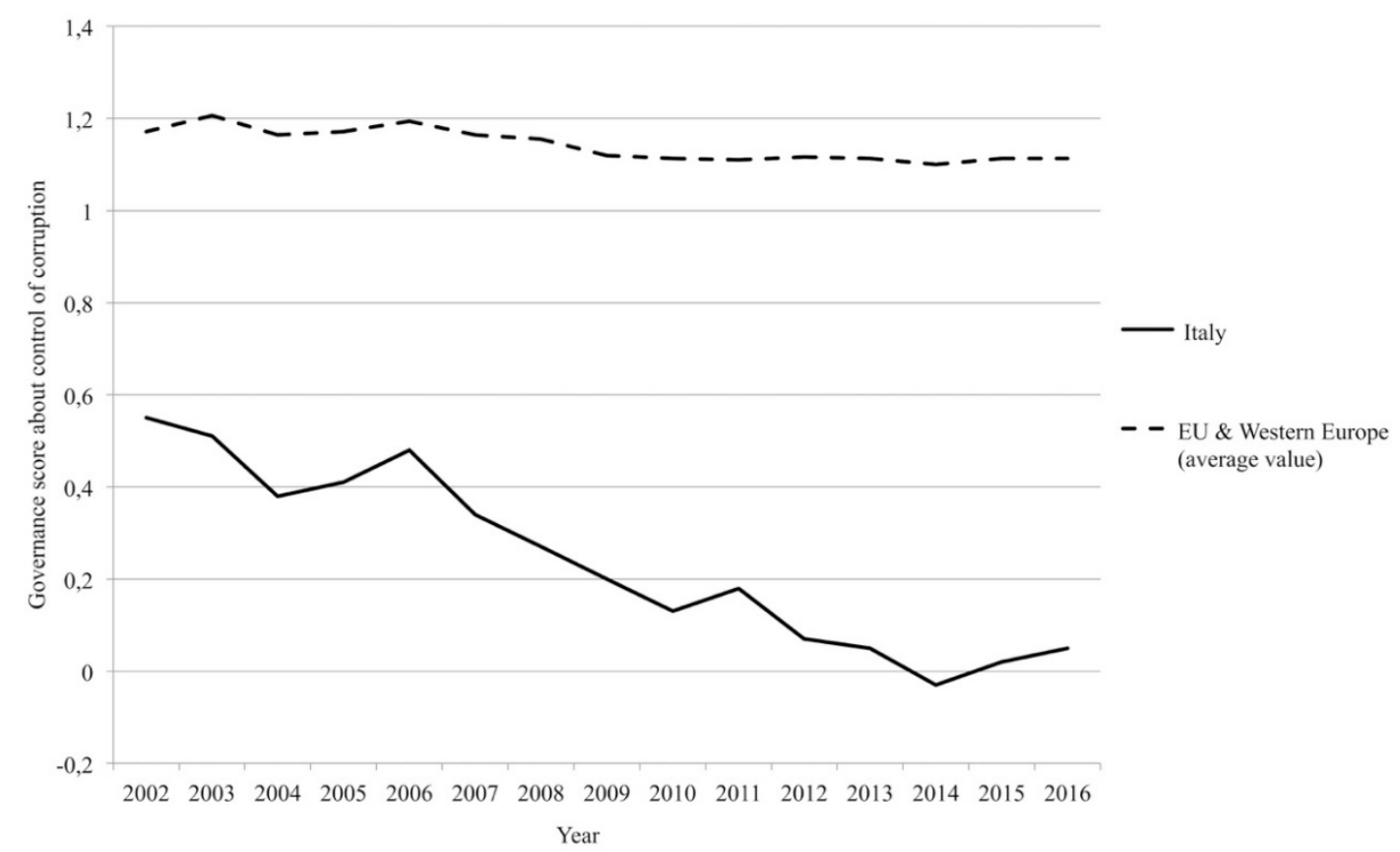

Figure 2. Control of corruption by the Italian government and by the EU and Western Europe governments (average value) for the period between 2002 and 2016. Source: World Bank (2016), Worldwide Governance Indicators.

\section{Perceived Exogenous and Endogenous Obstacles and Entrepreneurial Intention}

Several scholars have identified multiple variables or factors than seem responsible for hindering a person's propensity towards an entrepreneurial career. Indeed, these factors are called entrepreneurial barriers and are seen as negative antecedents of entrepreneurial intention (Fatoki 2010; Neneh 2014; Samuel et al. 2013). More specifically, Keat and Ahmad (2012) proposed classifying these entrepreneurial obstacles into three categories: 
- Exogenous obstacles, representing characteristics of the entrepreneurial ecosystem such as bureaucracy, taxation on revenue and income, access to credit, the presence of competitors, efficiency of the judicial system;

- Personal exogenous factors, linked to the amount and quality of individual competencies such as resiliency to stress, fear of failure, a perceived lack of strategic vision';

- Operative and financial endogenous obstacles, attributable to the person's individual financial situation such as lack of funds and capital, elevated start-up costs.

It has been observed that perceived obstacles act as a significant inhibitor of entrepreneurial intention since they give young entrepreneurs a sense of disheartenment in regard to their entrepreneurial dreams, as a consequence of a perceived lack of governmental support, laws and norms perceived as obscure and unreasonable, and doubts and uncertainty about their own competencies (Kautonen et al. 2011; Neneh 2014; Postigo et al. 2006). In their work, Fatoki and Chindoga (2011) underlined how a large amount of entrepreneurial intention variance in college students was explained by factors related to difficulties in obtaining credit, a perceived lack of entrepreneurial competencies, low risk propensity, lack of governmental support and market impenetrability. Nawaser et al. (2011) suggested dividing the perceived obstacles into two macro-categories:

- Factors that demotivate individuals, such as a negative prediction of the success of their plans and actions;

- Perceived regulatory barriers, such as strict banking rules and trade regulations, which are thus labeled legal obstacles.

Nawaser et al. (2011) identified the fear of losing one's monetary and non-monetary resources in a bad investment as the biggest motivational obstacle to an entrepreneurial career, and strict bank rules as the biggest legal obstacle to financing a start-up. Overwork and government bureaucracy did not however seem to exert a negative influence on the start-up process. Keat and Ahmad (2012), instead, found that the biggest entrepreneurial inhibitor for the launching of a new entrepreneurial career was the perception of elevated market competitiveness. However, scholars have stated that these contrasting results regarding the influence of various endogenous and exogenous obstacles on entrepreneurial intentions could be the consequence of the different role each perceived obstacle plays in a specific context. In fact, many authors have stated that the perception of entrepreneurial barriers can differ significantly from country to country, and that is precisely why careful thought and contextualized entrepreneurial education are needed to provide potential entrepreneurs with the right tools to overcome these obstacles (Fatoki 2010; Fatoki and Chindoga 2011; Keat and Ahmad 2012; Nawaser et al. 2011).

We propose categorizing the perceived obstacles into two categories: exogenous obstacles linked to the particular political-social-economical context where the individual lives, and endogenous factors ascribable to internal individual variables. In light of the foregoing considerations, we hypothesized that:

Hypothesis 3a. The perceived exogenous obstacle is a negative antecedent of entrepreneurial intention; that is, a higher level of perceived exogenous obstacles predicts a lower level of entrepreneurial intention.

Hypothesis $3 \mathbf{b}$. The perceived endogenous obstacle is a negative antecedent of entrepreneurial intention; that is, a higher level of perceived endogenous obstacles predicts a lower level of entrepreneurial intention.

\section{Materials and Methods}

\subsection{Subjects}

The subjects of this study were students and recent graduates registered at the Placement Service of a public University Department in Italy. Of a total of 265 registered subjects, 154 participated 
in the study ( $58 \%$ of the registered subjects). One of them was excluded as he already had some entrepreneurial experience. The final sample was made up of 153 college students $(70.6 \%)$ and graduates $(29.4 \%), 36.6 \%$ male and $63.4 \%$ female. The great majority of subjects were less than 29 years old $(86.6 \%)$ and only $3.3 \%$ was over 35 years old. Most $(90.8 \%)$ were unemployed or searching for their first job at the time the questionnaires were administered. The respondents had not participated in any previous entrepreneurship education course and nor did they have any previous self-employment experience.

\subsection{Tools}

In order to test the research hypotheses, a questionnaire divided into two sections was adopted. The first section measured the following constructs: entrepreneurial self-identity, entrepreneurial intention, perceived endogenous obstacles to entrepreneurship, perceived exogenous obstacles to entrepreneurship, and perceived corruption of the entrepreneurial ecosystem. The second section explored demographic data such as age, university coursework, previous work experience, etc. The 32 items used for the five factors of the first section were measured with a seven-point Likert-type scale (the questionnaire items are listed in the Appendix A), ranging from 1 (do not agree at all) to 7 (totally agree). More specifically, the questionnaire was organized as follows:

- The first factor measured entrepreneurial intention. The six-item scale was adapted from the entrepreneurial intention subscale of the Entrepreneurial Intention Questionnaire (EIQ) developed by Liñán and Chen (2009). The subjects were asked to indicate how much they agreed with six statements. For example, "I'll do everything I can to become an entrepreneur."

- The second factor measured entrepreneurial self-identity. The four-item scale was adapted from the Self-Identity Scale developed by Terry et al. (1999). The respondents were asked to indicate how much they agreed with the four statements regarding their self-perception. For example, "I consider myself as having entrepreneurial characteristics."

- The third factor measured the perceived endogenous obstacles to entrepreneurship. The five-item scale was developed based on Keat and Ahmad (2012). The respondents were asked to indicate how much they agreed with five statements. For example, they had to respond to the following statement: "I have low propensity to risk."

- The fourth factor measured perceived exogenous obstacles to entrepreneurship. The ten-item scale was developed based on Keat and Ahmad (2012). The respondents were asked to indicate how much they agreed with ten statements. For example, they had to respond to the following statement: "According to you, how much can this contextual factor dissuade you from starting your own firm: high interest rates on bank loans."

- The fifth factor measured the perceived corruption of the entrepreneurial ecosystem. The seven-item scale was proposed by the authors. The respondents were asked to indicate how much they agreed with seven statements. For example, they had to respond to the following statement: "It's very hard to manage a successful firm without bribing someone".

\subsection{Procedures}

The subjects were asked to answer the questions posed in an online questionnaire. The data were analyzed by IBM SPSS v. 23 to highlight certain descriptive statistics related to the questionnaire and the Cronbach's Alpha, as well as conduct a hierarchical multiple regression analysis on variables predicting entrepreneurial intentions. Prior to conducting the hierarchical multiple regression analysis, the most relevant assumptions of this statistical analysis were tested. Firstly, the sample size was considered to evaluate its adequacy given the number of independent variables to be included in the analysis (Tabachnick and Fidell 2001). The assumption of singularity was also explored to rule out that the independent variables were not a combination of other independent variables. A range of skewness and kurtosis between -2 and +2 was considered acceptable to confirm the normal univariate 
distribution of the questionnaire variables (George and Mallery 2010). Cronbach's Alpha values greater than 0.70 were considered acceptable (Cortina 1993). An examination of correlations of the independent variables was made and the assumption of multicollinearity was tested (Bryman and Cramer 2005; Field 2005). The demographic variables were entered at stage one of the hierarchical multiple regression to control for sex $(\mathrm{M}=1, \mathrm{~F}=2)$, age (in years), academic status (college student = 1 , graduated $=2$ ), past work experience (in years), father's career (other jobs $=1$, entrepreneurs $=2$ ), mother's career (other jobs $=1$, entrepreneurs $=2$ ).

\section{Results}

\subsection{Descriptive Statistics}

As Table 1 shows, the Cronbach's Alpha coefficients of the overall questionnaire factors were higher than 0.80 demonstrating that the model variables possessed adequate internal consistency. An examination of the correlations revealed no variables were highly correlated, with the exception of Perceived Corruption of Entrepreneurial Ecosystem with Perceived Endogenous Obstacles $(r=0.257$, $p<0.01)$ and Entrepreneurial Intention with Entrepreneurial Self-Identity $(\mathrm{r}=0.727, p<0.001)$. A low correlation was observed between Entrepreneurial Intention and Perceived Endogenous Obstacles $(\mathrm{r}=-0.144, p<0.10)$. The values for skewness of the probability distribution of all the model variables ranged between -0.733 and 0.437 (SD (max value) $=0.196)$ and the values for kurtosis of the probability distribution of all the model variables ranged between 1.032 and -0.747 ( $\max \mathrm{SD}=0.390)$, therefore it could be assumed there was a normal univariate distribution of all the questionnaire variables.

Table 1. Means, standard deviations, coefficient alphas and intercorrelations of the study variables.

\begin{tabular}{|c|c|c|c|c|c|c|c|}
\hline & Mean & SD & 1 & 2 & 3 & 4 & 5 \\
\hline 1. Perceived Exogenous Obstacles & 4.93 & 0.95 & $(0.83)$ & & & & \\
\hline 2. Perceived Endogenous Obstacles & 2.79 & 1.13 & 0.09 & $(0.81)$ & & & \\
\hline 3. Perceived Corruption of $\mathrm{EE}^{\mathrm{a}}$ & 3.84 & 1.40 & 0.08 & $0.26^{* * *}$ & $(0.89)$ & & \\
\hline 4. Entrepreneurial Intention & 4.28 & 1.55 & 0.01 & $-0.14 *$ & 0.05 & $(0.96)$ & \\
\hline 5. Entrepreneurial Self-Identity & 3.23 & 1.33 & 0.07 & -0.10 & -0.10 & $0.73 * * * *$ & $(0.85)$ \\
\hline
\end{tabular}

Due the high correlation between Entrepreneurial Intention and Entrepreneurial Self-Identity, all items linked to these two factors were evaluated simultaneously in a confirmatory factor analysis (CFA) to assess the construct and discriminant validity of these two scales. The CFA demonstrated a reasonably adequate fit based on commonly accepted criteria (Hu and Bentler 1999; Kline 2016), $\chi^{2}$ $(33)=74.27, p=0.000$; Comparative Fit Index $(\mathrm{CFI})=0.97$; Tucker-Lewis Index (TLI) = 0.96; root mean square error of approximation (RMSEA) $=0.09$. A covariance between the standard errors of items 5 and 6 of the entrepreneurial intention scale was added, following the modification index report of the structural equation model. All factor loadings were statistically significant for their respective construct at $p<0.001$, and all items generated satisfactory standardized average variance extracted estimates for their respective construct. More specifically, the standardized regression weights for the Entrepreneurial Self-Identity factor ranged between 0.578 and 0.943 and the standard errors were acceptable (range between 0.13 and 0.15); the standardized regression weights for entrepreneurial intention factor ranged between 0.818 and 0.952 and the standard errors were acceptable (range between 0.07 and 0.09 ).

\subsection{Hierarchical Multiple Regression Analysis}

The sample size of 153 was considered adequate given the four independent variables to be included in the hierarchical multiple regression analysis. Due the presence of a statistically significant correlation between the two independent variables of entrepreneurial intention, that is, 
Perceived Corruption and Perceived Endogenous Obstacles $(r=0.257, p<0.01)$, the assumption of multicollinearity was tested. The collinearity statistics were all within accepted limits (Perceived Exogenous Obstacles, tolerance $=0.982, \mathrm{VIF}=1.018$; Perceived Endogenous Obstacles, tolerance $=$ 0.919, VIF = 1.088; Perceived Corruption, tolerance $=0.925$, VIF $=1.081$; Self-Identity, tolerance $=0.974$, $\mathrm{VIF}=1.027$ ) and therefore the assumption of multicollinearity was considered justified.

A four-stage hierarchical multiple regression was conducted with Entrepreneurial Intention as the dependent variable (Table 2). The demographic variables were entered at stage one of the regression to control for sex, age, academic status, past work experience, father's career and mother's career. The hierarchical multiple regression analysis revealed that at this stage one, Past Work Experience and Father's Career contributed significantly to the regression model $(\mathrm{F}[6,146]=2.46, p<0.05)$ and accounted for $5.4 \%$ of the variation in Entrepreneurial Intention. At stage two, the addition of the Entrepreneurial Self-Identity variable to the regression model explained an additional $49.0 \%$ of the variation in Entrepreneurial Intention and the change in $\mathrm{R}^{2}$ was significant $(\mathrm{F}[1,145]=157.92, p<$ 0.001). At stage three, the addition of Perceived Corruption of the Entrepreneurial Ecosystem variable to the regression model explained an additional $1.2 \%$ of the variation in Entrepreneurial Intention and the change in $\mathrm{R}^{2}$ was significant $(\mathrm{F}[1,144]=4.78, p<0.05)$. Finally, at stage four, the addition of Perceived Exogenous Obstacles and Perceived Endogenous Obstacles variables to the regression model explained an additional $0.4 \%$ of the variation in Entrepreneurial Intention and the change in $\mathrm{R}^{2}$ was not significant $(\mathrm{F}[2,142]=1.68, p=0.19)$.

Table 2. Summary of hierarchical multiple regression analysis for variables predicting entrepreneurial intentions.

\begin{tabular}{|c|c|c|c|c|c|c|c|c|}
\hline \multirow[b]{2}{*}{ Variables } & \multicolumn{2}{|l|}{ Model 1} & \multicolumn{2}{|l|}{ Model 2} & \multicolumn{2}{|l|}{ Model 3} & \multicolumn{2}{|l|}{ Model 4} \\
\hline & B & SE & B & SE & B & SE & B & SE \\
\hline Constant & $3.59 * * * *$ & 0.96 & $2.71^{* * * *}$ & 0.67 & $2.03 * * *$ & 0.73 & $2.52 * * *$ & 0.85 \\
\hline Demographic Variables & & & & & & & & \\
\hline Sex & -0.05 & 0.26 & -0.00 & 0.18 & -0.01 & 0.18 & -0.01 & 0.18 \\
\hline Age & -0.11 & 0.16 & $-0.19^{* * *}$ & 0.11 & $-0.19^{* * *}$ & 0.11 & $-0.19^{* * *}$ & 0.11 \\
\hline Academic Status & -0.09 & 0.30 & -0.02 & 0.21 & 0.00 & 0.21 & -0.01 & 0.21 \\
\hline Past Work Exp. & $0.23 * *$ & 0.11 & $0.12 *$ & 0.08 & $0.12 * *$ & 0.08 & $0.11 *$ & 0.08 \\
\hline Father's Career & $0.13 *$ & 0.35 & 0.01 & 0.25 & 0.02 & 0.25 & 0.03 & 0.25 \\
\hline Mother's Career & 0.08 & 0.64 & -0.08 & 0.45 & -0.08 & 0.45 & -0.09 & 0.45 \\
\hline ES-I ${ }^{a}$ & & & $0.74^{* * * *}$ & 0.07 & $0.75^{* * * *}$ & 0.07 & $0.74^{* * * *}$ & 0.07 \\
\hline PCofEE $^{b}$ & & & & & $0.12^{* *}$ & 0.06 & $0.15^{* * *}$ & 0.06 \\
\hline $\mathrm{PEXOO}^{\mathrm{C}}$ & & & & & & & -0.01 & 0.09 \\
\hline PENDO $^{d}$ & & & & & & & $-0.10 *$ & 0.08 \\
\hline $\mathrm{R}^{2}$ & 0.09 & & 0.56 & & 0.58 & & 0.59 & \\
\hline Adjusted $\mathrm{R}^{2}$ & 0.05 & & 0.54 & & 0.56 & & 0.56 & \\
\hline $\mathrm{df}$ & 146 & & 145 & & 144 & & 142 & \\
\hline $\mathrm{F}^{\mathrm{e}}$ & $2.46^{* *}$ & & $157.92^{* * * *}$ & & $4.78^{* *}$ & & 1.68 & \\
\hline
\end{tabular}

Note: $\mathrm{N}=153$; $\mathrm{B}$ = standardized beta coefficient; $\mathrm{SE}=$ standard error; ${ }^{\mathrm{a}} \mathrm{ES}-\mathrm{I}=$ Entrepreneurial Self-Identity;

b PCofEE = Perceived Corruption of Entrepreneurial Ecosystem; ${ }^{c}$ PEXOO = Perceived Exogenous Obstacles;

$\mathrm{d}$ PENDO = Perceived Endogenous Obstacles; $\mathrm{df}=$ degrees of freedom; ${ }^{\mathrm{e}} \mathrm{F}=\mathrm{F}$ for change in $\mathrm{R}^{2} .{ }^{*} p<0.10,{ }^{* *} p<0.05$, ${ }^{* * *} p<0.01,{ }^{* * * *} p<0.001$.

It is worth noting that when the Entrepreneurial Self-Identity variable was included in stage two of the regression model, the Father's Career variable was no longer a significant predictor of Entrepreneurial Intention, whereas the Age variable became a significant predictor of Entrepreneurial Intention.

As the regression model at stage four depicted in Table 2 shows, the most important predictor of Entrepreneurship Intention was clearly Entrepreneurial Self-Identity $(B=0.739, p<0.001)$, which by itself accounted for $49 \%$ of the variation in Entrepreneurship Intention, whereas Perceived Corruption of Entrepreneurial Ecosystem $(B=-0.739, p<0.001)$ was a significant but moderate predictor of Entrepreneurship Intention. The four independent variables jointly accounted for $56 \%$ of the variance in Entrepreneurial Intention. Finally, we can observe that the Perceived Endogenous Obstacles variable 
was a significant predictor of Entrepreneurial Intention $(\mathrm{B}=0.147, p<0.01)$ although, as already mentioned, the change in $\mathrm{R}^{2}$ due to the addition of both Perceived Endogenous and Exogenous Obstacles to the regression model at stage four was not significant.

\section{Discussion}

An analysis of the results of this research clearly shows that the entrepreneurial self-identity construct is the key antecedent of entrepreneurial intention. Hence, Hypothesis 1 was fully confirmed. This result is in line with the previous work found in the literature concerning the effect of identity perception on behavioral intentions (Rise et al. 2010) and on entrepreneurial behaviors and intentions (Conger et al. 2012; Fauchart and Gruber 2011). With regard to the intensity of the causal relationship between entrepreneurial self-identity and entrepreneurial intention, it is possible to hypothesize that such a result depends on the unique, socially-shared and recognized characteristics typically associated with an up-to-date entrepreneurial career. Many scholars have underlined how these characteristics are attributable to the fact that entrepreneurs are often forced to live with high levels of uncertainty about the economic sustainability of their company, riding the unpredictable waves of an unstable market that is subject to continuous changes in regulatory, social, and macro-economic fields. Since an entrepreneur must come to terms with these situations, he/she must develop personal and behavioral strategies in order to manage the stress and anxiety generated by the constant strain of being continuously committed to managing processes of innovation through the adoption of new technology and innovative cultural models (Greenwood and Hinings 1996; Hogan and Coote 2014; Lüscher and Lewis 2008; Pettigrew et al. 2001; Schein 1990; Weick and Quinn 1999). These views, commonly shared among the well-educated population, would consider driven toward an entrepreneurial career only those individuals who strongly perceive themselves as carriers of an identity characterized by certain personal and behavioral features, such as being oriented to an entrepreneurial career because of one's authentic and robust entrepreneurial intention. Since entrepreneurial intentions are the strongest antecedent of entrepreneurial behavior, they appear as the concrete representations of an individual's will to become an entrepreneur through self-confirmation of the fact that one possesses the typical characteristics of this profession (Bagozzi et al. 1989).

Hypothesis 2 was confirmed. The positive causal relationship between perceived corruption and entrepreneurial intention-where a higher level of perceived corruption predicts a higher level of entrepreneurial intention-is in line with the study conducted by El Harbi and Anderson (2010) and seems to reveal college students' and graduates' propensity to perceive corruption as something capable of generating a "grease the wheel" effect (Hanoteau and Vial 2014). From this point of view, these individuals may consider corruption as an acceptable strategy that entrepreneurs might adopt in order to easily overcome governmental norms and rules and other restrictions posed by regulations on managing a firm. This consideration becomes more relevant if we take into account the perceived corruption indicators that depict Italy as characterized by a high level of perceived corruption. It should not be too difficult to hypothesize how the efforts made to restrict the corruption phenomenon could clash with the resistance generated by the constant process of integration of perceived corruption into the national culture. At the end of this process, corruption might be viewed as an unavoidable and inescapable dimension linked to all entrepreneurial activity (Aidis et al. 2012; Djankov et al. 2005). Moreover, we want to point out that in our study we have simply investigated the relationship between the perception of corruption of the entrepreneurial ecosystem and individual entrepreneurial intention, without focusing on the effects such perception may have on the real entrepreneurial dynamics in a country. The "grease the wheel" effect found in our study must not be generalized to the hypothesis that corruption may have an economic "grease the wheel" effect on the economic fabric of Italy. However, these results should be considered as a wake-up call, prompting us to study more closely young people's social representation of entrepreneurial careers and of entrepreneurship in general. The risk, in this specific context, is that this social representation could be a catalyst in the process 
of integrating corruption into the national culture, thus frustrating many of the efforts made by the government to fight the phenomenon of corruption.

Hypothesis 3a was not confirmed. This was a surprise since the result is strongly discordant with the results found in literature (Fatoki 2010; Nawaser et al. 2011; Neneh 2014; Samuel et al. 2013). However, the fact that the causal relationship between perceived exogenous obstacles and entrepreneurial intention was not statistically significant could be explained by the demographic characteristics of our sample. More specifically, it is possible to imagine that young college students and graduates-Mostly under 29 years old and with no previous work experience or specifically entrepreneurship-related education-do not have a concrete perception of what the real effects on company sustainability of variables such as "high interest rates on bank loans" or "lack of governmental support for creating a start-up" are, since they have neither direct previous experience of these issues, nor indirect experience through the psychological process of vicarious experience (Bandura 1986). This possible explanation seems to be supported by the fact that in our work, previous experience has shown little statistically significant impact on individuals' entrepreneurial intention.

Finally, Hypothesis $3 b$ was weakly confirmed. This result showed a weak statistically significant causal relationship between endogenous perceived obstacles and entrepreneurial intention and is in line with the work of Keat and Ahmad (2012). This relationship reveals that an individual's perception about their own competencies, abilities, and personal characteristics may indeed exert an influence on entrepreneurial intention. However, it is important to underline that the weakness of such a relationship might be caused by a partial dimensional overlap between the constructs of entrepreneurial self-identity and the perception of endogenous obstacles, since both variables are attributable to self-perception of an individual's inner world, even if they are obviously characterized by an opposite impact on entrepreneurial intention.

\section{Conclusions}

We wish to draw some conclusions based on the evidence from our research. In general terms, we consider the results of our research a step forward in discovering informal effects that could impact an individual's entrepreneurial intention. Since entrepreneurial self-identity plays an important role in driving people to an entrepreneurial career, public decision-makers and scholars are obliged to reflect deeply on which educational practices help young people develop such a perception of self-identity. If it is true that entrepreneurial self-identity plays a major role in influencing entrepreneurial intention, then educational programs of all grades of the school system should allocate enough resources to accompany and foster the individual in the slow development of his/her identity and, if appropriate, an entrepreneurial self-identity that is unique and different from the others (Donnellon et al. 2014; Zhang et al. 2014). This approach may allow people to strengthen their perception of possessing entrepreneurial characteristics. It is very important, we repeat, to spread this policy at all levels of the education system, since it is well known that educational practices oriented to shaping identity perceptions are more successful when they are employed for many years, starting at a young age. Therefore, the discussion of an entrepreneurial educational system should not be only linked to the choice of innovative methodologies, but it should also be oriented towards a new educational model of development that sustains individuals who may feel like potential entrepreneurs (Liñán et al. 2018).

As previously underlined, it is important to stress the potential role of perceived corruption within an individual representation of the entrepreneurial ecosystem as an enabler of a vicious circle. In such a vicious circle or reinforcing loop, the perceived corruption fosters the development of corrupt behaviors that, in turn, end up reinforcing the perception of the pervasiveness of the phenomenon of corruption in the entrepreneurial ecosystem itself, since they become considered "typical" behaviors associated with entrepreneurial activity. As a consequence, Italy might not be able to free itself of corruption due to this chain of inter-related factors. In this sense, it is appropriate for the Italian government to implement activities and strategies to effectively fight and prevent the phenomenon of corruption, both in the judicial sphere and in the social and cultural fabric of the country. In fact, it 
has been demonstrated that perceptions of successful anti-corruption efforts made by the government may have a direct significant impact on fostering an individual's propensity to becoming entrepreneur, thus indirectly contributing to general economic growth (Anokhin and Schulze 2009).

Furthermore, the results regarding the effect of entrepreneurial self-identity and of perceived corruption of entrepreneurial ecosystem on entrepreneurial intention could be transferred to other countries. Moreover, the "grease the wheel" effect-subtended by the positive effect of perceived corruption of the entrepreneurial ecosystem on entrepreneurial intention-might be observed in all those countries where corruption is a widespread phenomenon throughout the economic sector and anti-corruption efforts of the government are perceived as insufficient and ineffective. By merely focusing our consideration at the European level of analysis, countries such as Spain, Slovakia, Croatia, Greece, Romania, Hungary, and Bulgaria-all suffering from a high level of pervasive corruption within their economy (Transparency International 2017)—could display similar dynamics of social representations of the role of perceived corruption of the entrepreneurial ecosystem on entrepreneurial intention. In light of this consideration, scholars should carefully carry out future comparative studies in order to confirm these hypotheses.

Funding: This research received no external funding.

Conflicts of Interest: The authors declare no conflict of interest.

\section{Appendix A The Questionnaire Items}

\section{Factor 1: Entrepreneurial Intention}

Please indicate your level of agreement with the following statements:

- I'm ready to work very hard in order to become an entrepreneur

- My professional goal is to become an entrepreneur

- I'm very determined to start my own firm in the future

- I will do everything I can to start and manage my own firm

- I have thought very carefully about starting my own firm

- I have the inflexible intention of starting my own firm some day

Factor 2: Entrepreneurial Self-Identity

Looking at your past behavior, express your level of agreement with the following statements:

- I consider myself as an entrepreneur

- I consider myself as having the characteristics of an entrepreneur

- Becoming an entrepreneur will perfectly represent who I am

- If I had to give up the idea of becoming an entrepreneur, I would consider it as a failure

Factor 3: Perceived Exogenous Obstacles

In your opinion, how much can these contextual factors influence your decision to start your own firm? $(1=$ not at all; 7 = very much $)$

- High level of interest rates for bank loans

- High labor costs

- Strict and rigid bureaucratic regulations

- High taxes

- Lack of national support for starting a firm

- Strong competitors

- Inefficiency of the civil justice system 
- Lack of support from parents who work in the entrepreneurial field

- Difficulty of access to credit

- Lack of trustworthy partners

Factor 4: Perceived Endogenous Factors

In your opinion, how much can these personal factors influence your decision to start your own firm? $(1=$ not at all; $7=$ very much $)$

- I have serious problems managing stress

- Generally speaking, I am afraid of failure

- I have low entrepreneurial skills

- I have low levels of competence in planning and strategic vision

- I have low propensity to risk

Factor 5: Perceived Corruption within the Entrepreneurial Ecosystem

Please indicate your level of agreement with the following statements. We ask you to express your scores by keeping in mind what entrepreneurs typically do in your country and not what you would do if you were an entrepreneur.

- A successful entrepreneur can overcome difficulties only through his political alliances

- If an honest entrepreneur wants to expand his firm, he must make a deal with special interest groups or powerful people

- It's very hard to manage a successful firm without bribing someone

- It's very hard to manage a successful firm without making compromises with political interest groups

- If a successful entrepreneur wants desperately to achieve his/her goals, he/she should not be afraid to take economic shortcuts, even illegal ones

- It's very hard to manage a successful firm without making a deal with organized criminal associations

- A successful entrepreneur must have a very good group of professionals available for strategic advice to avoid being sentenced for crimes he/she has committed

\section{References}

Aidis, Ruta, Saul Estrin, and Tomasz Marek Mickiewicz. 2012. Size matters: Entrepreneurial entry and government. Small Business Economics 39: 119-39. [CrossRef]

Aidt, Toke S. 2009. Corruption, institutions, and economic development. Oxford Review of Economic Policy 25: 271-91. [CrossRef]

Allini, Alessandra, Luca Ferri, Marco Maffei, and Annamaria Zampella. 2017. The Effect of Perceived Corruption on Entrepreneurial Intention: Evidence from Italy. International Business Research 10: 75-86. [CrossRef]

Alsos, Gry Agnete, Tommy HøyvardeClausen, Ulla Hytti, and Sølvi Solvoll. 2016. Entrepreneurs' social identity and the preference of causal and effectual behaviours in start-up processes. Entrepreneurship and Regional Development 28: 234-58. [CrossRef]

Anokhin, Sergey, and William S. Schulze. 2009. Entrepreneurship, innovation, and corruption. Journal of Business Venturing 24: 465-76. [CrossRef]

Aparicio, Sebastian, David Urbano, and David Audretsch. 2016. Institutional factors, opportunity entrepreneurship and economic growth: Panel data evidence. Technological Forecasting and Social Change 102: 45-61. [CrossRef]

Bagozzi, Richard P., Johann Baumgartner, and Youjae Yi. 1989. An investigation into the role of intentions as mediators of the attitude-behavior relationship. Journal of Economic Psychology 10: 35-62. [CrossRef] 
Bandura, Albert. 1986. Social Foundations of thought and Action: A Social Cognitive Theory. Englewood Cliffs: Prentice-Hall, Inc.

Bowen, Harry P., and Dirk De Clercq. 2008. Institutional context and the allocation of entrepreneurial effort. Journal of International Business Studies 39: 747-67. [CrossRef]

Brändle, Leif, Elisabeth SC Berger, Stephan Golla, and Andreas Kuckertz. 2018. I am what I am-How nascent entrepreneurs' social identity affects their entrepreneurial self-efficacy. Journal of Business Venturing Insights 9: 17-23. [CrossRef]

Bryman, Alan, and Duncan Cramer. 2005. Quantitative Data Analysis with SPSS 12 and 13. London: Routledge.

Burke, Peter J. 2004. Identities and social structure: The 2003 Cooley-Mead award address. Social Psychology Quarterly 67: 5-15. [CrossRef]

Burke, Peter J. 2007. Identity control theory. In The Blackwell Encyclopedia of Sociology. Edited by G. Ritzer. Oxford: Blackwell Publishing Ltd., pp. 2202-207.

Cardon, Melissa S., Joakim Wincent, Jagdip Singh, and Mateja Drnovsek. 2009. The nature and experience of entrepreneurial passion. Academy of management Review 34: 511-32. [CrossRef]

Conger, Michael, Jeffrey G. York, and Tyler Wry. 2012. We do what we are: Entrepreneurship as the expression of values and identity. Working paper. University of Colorado.

Cortina, Jose M. 1993. What is coefficient alpha? An examination of theory and applications. Journal of Applied Psychology 78: 98-104. [CrossRef]

Del Mar Salinas-Jiménez, Ma, and Javier Salinas-Jiménez. 2007. Corruption, efficiency and productivity in OECD countries. Journal of Policy Modeling 29: 903-15. [CrossRef]

Djankov, Simeon, Edward Miguel, Yingyi Qian, Gerard Roland, and Ekaterina Zhuravskaya. 2005. Who are Russia's entrepreneurs? Journal of the European Economic Association 3: 587-97. [CrossRef]

Donnellon, Anne, Susanne Ollila, and Karen Williams Middleton. 2014. Constructing entrepreneurial identity in entrepreneurship education. The International Journal of Management Education 12: 490-99. [CrossRef]

Dreher, Axel, and Martin Gassebner. 2013. Greasing the wheels? The impact of regulations and corruption on firm entry. Public Choice 15: 413-32. [CrossRef]

Dutta, Nabamita, and Russell Sobel. 2016. Does corruption ever help entrepreneurship? Small Business Economics 47: 179-99. [CrossRef]

Engle, Robert L., Nicolay Dimitriadi, Jose V. Gavidia, Christofer Schlaegel, Servane Delanoe, Irene Alvarado, He Xiaohong, Samuel Buame, and Brigitta Wolff. 2010. Entrepreneurial intent: A twelve-country evaluation of Ajzen's model of planned behavior. International Journal of Entrepreneurial Behavior and Research 16: 35-57. [CrossRef]

Estrin, Saul, Klaus E. Meyer, and Maria Bytchkova. 2006. Entrepreneurship in transition economies. In The Oxford Handbook of Entrepreneurship. Oxford: Oxford University Press, pp. 693-725.

Estrin, Saul, Julia Korosteleva, and Tomasz Mickiewicz. 2013. Which institutions encourage entrepreneurial growth aspirations? Journal of Business Venturing 28: 564-80. [CrossRef]

Fatoki, Olawale Olufunso. 2010. Graduate entrepreneurial intention in South Africa: Motivations and obstacles. International Journal of Business and Management 5: 87-98.

Fatoki, Olawale Olufunso, and Lynety Chindoga. 2011. An investigation into the obstacles to youth entrepreneurship in South Africa. International Business Research 4: 161-69. [CrossRef]

Fauchart, Emmanuelle, and Marc Gruber. 2011. Darwinians, communitarians, and missionaries: The role of founder identity in entrepreneurship. Academy of Management Journal 54: 935-57. [CrossRef]

Festinger, Leon. 1957. A Theory of Cognitive Dissonance. Stanford: Stanford University Press.

Field, Andy. 2005. Discovering Statistics Using SPSS. London: Sage Publications. [CrossRef]

George, Darren, and Paul Mallery. 2010. SPSS for Windows Step by Step: A Simple Guide and Reference, 18.0 Update, 11th ed. Upper Saddle River: Prentice Hall Press.

Glaeser, Edward L., and Raven E. Saks. 2006. Corruption in America. Journal of Public Economics 90: 1053-72. [CrossRef]

Greenwood, Royston, and Christopher R. Hinings. 1996. Understanding Radical Organizational Change: Bringing together the Old and the New Institutionalism. The Academy of Management Review 21: 1022-54. [CrossRef]

Hanoteau, Julien, and Virginie Vial. 2014. Grease or Sand the Wheel? The Effect of Individual Bribes on the Drivers of Aggregate Productivity Growth. Journal of Indonesian Economy and Business 29: 1-16. [CrossRef] 
El Harbi, Sana, and Alistair R. Anderson. 2010. Institutions and the shaping of different forms of entrepreneurship. Journal of Socio-Economics 39: 436-44. [CrossRef]

Hoang, Ha, and Javier Gimeno. 2010. Becoming a founder: How founder role identity affects entrepreneurial transitions and persistence in founding. Journal of Business Venturing 25: 41-53. [CrossRef]

Hofstede, Geert, Niels G. Noorderhaven, A. Roy Thurik, Lorraine M. Uhlaner, Alexander RM Wennekers, and Ralph E. Wildeman. 2004. Culture's role in entrepreneurship: Self-employment out of dissatisfaction. In Innovation, Entrepreneurship and Culture: The Interaction between Technology, Progress and Economic Growth. Edited by Brown Terrence and Jan M. Ulijn. Cheltenham and Brookfield: Edward Elgar, pp. 162-204.

Hogan, Suellen J., and Leonard V. Coote. 2014. Organizational culture, innovation, and performance: A test of Schein's model. Journal of Business Research 67: 1609-21. [CrossRef]

Holcombe, Randall G. 1998. Entrepreneurship and economic growth. The Quarterly Journal of Austrian Economics 1 : 45-62. [CrossRef]

Hu, Li-tze, and Peter M. Bentler. 1999. Cutoff criteria for fit indexes in covariance structure analysis: Conventional criteria versus new alternatives. Structural Equation Modeling: A Multidisciplinary Journal 6: 1-55. [CrossRef]

Hunt, Jennifer, and Sonia Laszlo. 2012. Is bribery really regressive? Bribery's costs, benefits, and mechanisms. World Development 40: 355-72. [CrossRef]

Kautonen, Teemu, Erno T. Tornikoski, and Ewald Kibler. 2011. Entrepreneurial intentions in the third age: The impact of perceived age norms. Small Business Economics 37: 219-34. [CrossRef]

Keat, Yeng, and Shuhymee Ahmad. 2012. A study among university students in business start-ups in Malaysia: Motivations and obstacles to become entrepreneurs. International Journal of Business and Social Science 3: 181-92.

Kline, R. B. 2016. Principles and Practice of Structural Equation Modeling. New York: Guilford Publications.

$\mathrm{Li}$, Shaomin, and Jun $\mathrm{Wu}$. 2010. Why some countries thrive despite corruption: The role of trust in the corruption-efficiency relationship. Review of International Political Economy 17: 129-54. [CrossRef]

Liñán, Francisco, and Yi-Wen Chen. 2009. Development and Cross-Cultural application of a specific instrument to measure entrepreneurial intentions. Entrepreneurship Theory and Practice 33: 593-617. [CrossRef]

Liñán, Francisco, Francesco Ceresia, and Antonio Bernal. 2018. Who Intends to Enroll in Entrepreneurship Education? Entrepreneurial Self-Identity as a Precursor. Entrepreneurship Education and Pedagogy 1: 222-42. [CrossRef]

Lucas, David S., and Caleb S. Fuller. 2017. Entrepreneurship: Productive, unproductive, and destructive-Relative to what? Journal of Business Venturing Insights 7: 45-49. [CrossRef]

Lüscher, Lotte S., and Marianne W. Lewis. 2008. Organizational Change and Managerial Sensemaking: Working through Paradox. The Academy of Management Journal 51: 221-40. [CrossRef]

Mauro, Paolo. 1995. Corruption and growth. The Quarterly Journal of Economics 110: 681-712. [CrossRef]

Nawaser, Khaled, Seyed Mohammad Sadeq Khaksar, Fatemeh Shaksian, and Asghar Afshar Jahanshahi. 2011. Motivational and legal barriers of entrepreneurship development. International Journal of Business and Management 6: 112-18. [CrossRef]

Neneh, Brownhilder Ngek. 2014. An assessment of entrepreneurial intention among university students in Cameroon. Mediterranean Journal of Social Sciences 5: 542-52. [CrossRef]

North, Douglass C. 1991. Institutions. Journal of Economic Perspectives 5: 97-112. [CrossRef]

North, Douglass C. 2005. Understanding the process of economic change. In Worlds of Capitalism. Institutions, Economic Performance and Governance in the Era of Globalization. Edited by Max Miller. London: Routledge, pp. 93-106.

Obschonka, Martin, Maximilian Goethner, Rainer K. Silbereisen, and Uwe Cantner. 2012. Social identity and the transition to entrepreneurship: The role of group identification with workplace peers. Journal of Vocational Behavior 80: 137-47. [CrossRef]

Olawale, Fatoki, and David Garwe. 2010. Obstacles to the growth of new SMEs in South Africa: A principal component analysis approach. African Journal of Business Management 4: 729-38.

Olken, Benjamin A. 2009. Corruption perceptions vs. corruption reality. Journal of Public Economics 93: 950-64. [CrossRef]

Paunov, Caroline. 2016. Corruption's asymmetric impacts on firm innovation. Journal of Development Economics 118: 216-31. [CrossRef] 
Pettigrew, Andrew M., Richard W. Woodman, and Kim S. Cameron. 2001. Studying Organizational Change and Development: Challenges for Future Research. The Academy of Management Journal 44: 697-713. [CrossRef]

Postigo, Sergio, Donato Iacobucci, and María Fernanda Tamborini. 2006. Undergraduate students as a source of potential entrepreneurs: A comparative study between Italy and Argentina. In International Entrepreneurship Education: Issues and Newness. Edited by Alain Fayolle and Heinz E. Klandt. Cheltenham: Elgar Publishing Limited, pp. 218-40. [CrossRef]

Rise, Jostein, Paschal Sheeran, and Silje Hukkelberg. 2010. The role of self-identity in the theory of Planned behaviour: A meta-analysis. Journal of Applied Social Psychology 40: 1085-105. [CrossRef]

Samila, Sampsa, and Olav Sorenson. 2011. Venture capital, entrepreneurship, and economic growth. The Review of Economics and Statistics 93: 338-49. [CrossRef]

Samuel, Yeboah Asuamah, Kumi Ernest, and Jacob Baffour Awuah. 2013. An assessment of entrepreneurship intention among Sunyani Polytechnic Marketing students. International Review of Management and Marketing 3: 37-49.

Sarasvathy, Saras D. 2001. Causation and effectuation: Toward a theoretical shift from economic inevitability to entrepreneurial contingency. Academy of management Review 26: 243-63. [CrossRef]

Schein, Edgar H. 1990. Organizational Culture. American Psychologist 45: 109-19. [CrossRef]

Sieger, Philipp, Marc Gruber, Emmanuelle Fauchart, and Thomas Zellweger. 2016. Measuring the social identity of entrepreneurs: Scale development and international validation. Journal of Business Venturing 31: 542-72. [CrossRef]

Stenholm, Pekka, Zoltan J. Acs, and Robert Wuebker. 2013. Exploring country-level institutional arrangements on the rate and type of entrepreneurial activity. Journal of Business Venturing 28: 176-93. [CrossRef]

Tabachnick, Barbara G., and Linda S. Fidell. 2001. Using Multivariate Statistics. Boston: Pearson, Education, Inc.

Tajfel, Henri, and John C. Turner. 1979. An integrative theory of intergroup conflict. In The Social Psychology of Intergroup Relations. Edited by William G. Austin and Stephen Worchel. Monterey: Brooks-Cole, pp. 33-47.

Terry, Deborah J., Michael A. Hogg, and Katherine M. White. 1999. The theory of planned behaviour: Self-identity, social identity and group norms. British Journal of Social Psychology 38: 225-44. [CrossRef] [PubMed]

Thornton, Patricia H., Domingo Ribeiro-Soriano, and David Urbano. 2011. Socio-cultural factors and entrepreneurial activity: An overview. International Small Business Journal 29: 105-18. [CrossRef]

Transparency International. 2017. Corruption Perception Index 2017. Available online: https:/ /www.transparency. org/news / feature/corruption_perceptions_index_2017 (accessed on 1 March 2018).

Watson, Tony J. 2013. Entrepreneurship in action: Bringing together the individual, organizational and institutional dimensions of entrepreneurial action. Entrepreneurship and Regional Development 25: 404-22. [CrossRef]

Weick, Karl E., and Robert E. Quinn. 1999. Organizational Change and Development. Annual Review of Psychology 50: 361-86. [CrossRef] [PubMed]

Wennekers, Sander, and Roy Thurik. 1999. Linking entrepreneurship and economic growth. Small Business Economics 13: 27-56. [CrossRef]

World Bank. 2016. Worldwide Governance Indicators. Available online: https:/ / datamarket.com/data/set/16uz/ control-of-corruption-estimate\#!ds=16uz!i75=5qanddisplay=table (accessed on 23 February 2018).

$\mathrm{Xu}$, Gang, and Go Yano. 2017. How does anti-corruption affect corporate innovation? Evidence from recent anti-corruption efforts in China. Journal of Comparative Economics 45: 498-519. [CrossRef]

Zhang, Ying, Geert Duysters, and Myriam Cloodt. 2014. The role of entrepreneurship education as a predictor of university students' entrepreneurial intention. International Entrepreneurship and Management Journal 10: 623-41. [CrossRef]

Zhou, Jessie Qi, and Mike W. Peng. 2012. Does bribery help or hurt firm growth around the world? Asia Pacific Journal of Management 29: 907-21. [CrossRef]

(C) 2019 by the authors. Licensee MDPI, Basel, Switzerland. This article is an open access article distributed under the terms and conditions of the Creative Commons Attribution (CC BY) license (http://creativecommons.org/licenses/by/4.0/). 